\title{
Empirical model for estimating global solar radiation for Braşov urban area
}

\author{
L. Coste ${ }^{1}$, E. Eftimie ${ }^{1}$ and C. Şerban ${ }^{1}$ \\ ${ }^{1}$ Department of Renewable Energy Systems and Recycling \\ Transilvania University of Braşov \\ B-dul Eroilor, 29, 500036 Braşov (România) Phone/Fax number: +0040 268412921 , \\ e-mail: andreea.coste@unitbv.ro,eftimiem@unitbv.ro and cristina.serban@unitbv.ro
}

\begin{abstract}
Physic - geographical and climatic features specific to Braşov urban area, makes necessary determination of a mathematical model to simulate in a precise manner the variation of global solar radiation.

In this way, the paper proposes a new empirical model to simulate the global solar radiation for Braşov urban area in clear sky conditions. The mathematical model was developed on the basis of 4 years database, respectively records of global solar radiation and meteorological parameters made by the meteorological weather station (starting October 2005).

Due to the interactions between the topography that characterizes Braşov area - that is a lowland situated at an altitude of over 700 meters, vegetation, the characteristic climate pattern, the dynamics of the atmosphere and aerosols it features a series of specific variation for solar radiation, that manifests daily, monthly and seasonally.

The present approach proposes one equation specific for every month of the year to simulate the global solar radiation; thus 12 simulation equations will be determined to estimate in a good manner the real global solar radiation. In order to validate the proposed empirical model two of the most utilized statistical indicators were used: Root Mean Square Error (RMSE) and Mean Bias Error (MBE).
\end{abstract}

\section{Key words}

Global solar radiation estimation, empirical model, MBE, RMSE

\section{Introduction}

In the last two decades a greate interest was manifested for the transformation of solar energy in energy utilized directly by the consumers, respectively in thermal energy trough solar collectors and in electric energy trough the photovoltaic panels.

Based on these two processes new applications are being developed in order to replace the existent ones that use energy obtained from fossil fuels. As a consequence the solar radiation study is a subject of real interest everywhere on the globe, along with other sources of renewable energy.

Solar radiation is available on the entire earth surface, but the quantity of radiation received differs depending on the geographical area, relief, atmospheric conditions and season. Thus it is essential to know the quantity and the variation of available solar radiation for a specific time duration, to develop solar energy applications (systems that can contain: solar collectors, photovoltaic panels) and new applications of theses, but even to estimate their efficiency.

Based on the RES type, designers need information about the global, direct solar radiation variation and in some particular cases about the diffuse component (designing an acclimatization system for a building).

Mathematical modeling of solar radiation represents an actual theme if it is taken into account the small number of meteorologic stations that offer measurements in the solar energy subject (global, direct and diffuse solar radiation on a horizontal surface and the sunshine period).

The technical literature proposes a series of empirical models to estimate the global, direct and diffuse solar radiation variation (Kasten, Adnot), ([1], [2]). Although these models are simple from a mathematical point of view, and these are easy to use in practice, they have the disadvantage of a limited area of applicability, these being specific to a particular area. The existent empirical models have been developed based on the specific measured data specific to a geographic area (solar radiation, temperature, humidity, etc.).

In this context the paper proposes a new empirical model for estimating global solar radiation for Braşov urban area, equations specific for every month of the year are proposed. 


\section{Global solar radiation}

"'Transilvania"' University of Braşov uses to measure the global solar radiation a solar sensor type BF3-UM-1.0 (the sensor measures the global, diffuse solar radiation and the sunshine duration). The measurements are carried out in a continuous manner since October 2005, being recorded at a 10 minute interval; the data are stored using a data logger.

The new proposed global radiation model estimates the solar radiation for clear sky conditions. Thus, the real data underlying the new model determination are data that comply with the WMO clear sky condition.

To select the clear sky days, from the entire database (since October 2005 to 2009) an extraction algorithm was utilized, algorithm presented in [3]. Based on the selected clear sky days the estimation equations for the global solar radiation were determined specific for each month of the year.

The estimation equations for global solar radiation are original and specific to every month of the year, and are characteristic to Braşov urban area; the expressions of these equations are presented in Table I.

Table I. - Specific equations for global radiation estimation for each month

\begin{tabular}{|c|c|}
\hline Month & Equation \\
\hline January & $\mathrm{G}_{\mathrm{h}}=\mathrm{I}_{\mathrm{o}} * \sin (\alpha) *\left(0,0457 * \mathrm{t} \_\right.$solar $\left.+0,0874\right)$ \\
\hline February & $\mathrm{G}_{\mathrm{h}}=\mathrm{I}_{\mathrm{o}} * \sin (\alpha) *\left(0,0373 * \mathrm{t} \_\right.$solar $\left.+0,2245\right)$ \\
\hline March & $\mathrm{G}_{\mathrm{h}}=\mathrm{I}_{\mathrm{o}} * \sin (\alpha) *\left(0,0291 * \mathrm{t} \_\right.$solar $\left.+0,3074\right)$ \\
\hline April & $\mathrm{G}_{\mathrm{h}}=\mathrm{I}_{\mathrm{o}} * \sin (\alpha) *\left(0,016 * \mathrm{t} \_\right.$solar $\left.+0,4773\right)$ \\
\hline May & $\mathrm{G}_{\mathrm{h}}=\mathrm{I}_{\mathrm{o}} * \sin (\alpha) *\left(0,0258 * \mathrm{t} \_\right.$solar $\left.+0,3623\right)$ \\
\hline June & $\mathrm{G}_{\mathrm{h}}=\mathrm{I}_{\mathrm{o}} * \sin (\alpha) *\left(0,02 * \mathrm{t} \_\right.$solar $\left.+0,446\right)$ \\
\hline July & $\mathrm{G}_{\mathrm{h}}=\mathrm{I}_{\mathrm{o}} * \sin (\alpha) *\left(0,03 * \mathrm{t} \_\right.$solar $\left.+0,28\right)$ \\
\hline August & $\mathrm{G}_{\mathrm{h}}=\mathrm{I}_{\mathrm{o}} * \sin (\alpha) *\left(0,0307 * \mathrm{t} \_\right.$solar $\left.+0,2741\right)$ \\
\hline September & $\mathrm{G}_{\mathrm{h}}=\mathrm{I}_{\mathrm{o}} * \sin (\alpha) *\left(0,031 * \mathrm{t} \_\right.$solar $\left.+0,2472\right)$ \\
\hline October & $\mathrm{G}_{\mathrm{h}}=\mathrm{I}_{\mathrm{o}} * \sin (\alpha) *\left(0,0247 * \mathrm{t} \_\right.$solar $\left.+0,3354\right)$ \\
\hline November & $\mathrm{G}_{\mathrm{h}}=\mathrm{I}_{\mathrm{o}} * \sin (\alpha) *\left(0,0255 * \mathrm{t} \_\right.$solar $\left.+0,302\right)$ \\
\hline December & $\mathrm{G}_{\mathrm{h}}=\mathrm{I}_{\mathrm{o}} * \sin (\alpha) *\left(0,0548 * \mathrm{t} \_\right.$solar $\left.-0,0676\right)$ \\
\hline
\end{tabular}

The estimation equations of the global radiation are expressed as functions depending on solar time, altitudinal angle and extraterrestrial radiation.

The global radiation depends on the geographical characteristics of the area trough the altitudinal angle; local particularization and seasonal are realized trough the solar time (a spring and autumn day have about 8 hours of sun and a maximum altitudinal angle of $45^{\circ}$; a summer day has 10 hours of sun and the maximum value for the altitudinal angle is $68^{\circ}$; for winter the maximum altitudinal angle is $22^{\circ}$ ).

Using the equations presented in Table I, in Figure 1 are presented the estimated radiation curves vs. the radiation real curves; the diagrams specific to June and July months have been plotted separately in Figure 2.

After the study of these diagrams, it can be noticed that the proposed monthly equations estimate in a correct manner the global radiation for values greater than 100 $\mathrm{W} / \mathrm{m}^{2}$; the estimated values are not widely spread from the $1: 1$ line, especially for the interval $100-800 \mathrm{~W} / \mathrm{m}^{2}$. A larger scattering of the simulated values towards the real values are observed for high values of the global solar radiation.

The points corresponding to higher values than $800 \mathrm{~W} / \mathrm{m}^{2}$ the global solar radiation values are situated below the 1:1 line that means that the estimated values are smaller than the real values.

The underestimation tendency is predominant for the summer days, when the altitudinal angle has high values, thereby the global solar radiation, Figure 2.

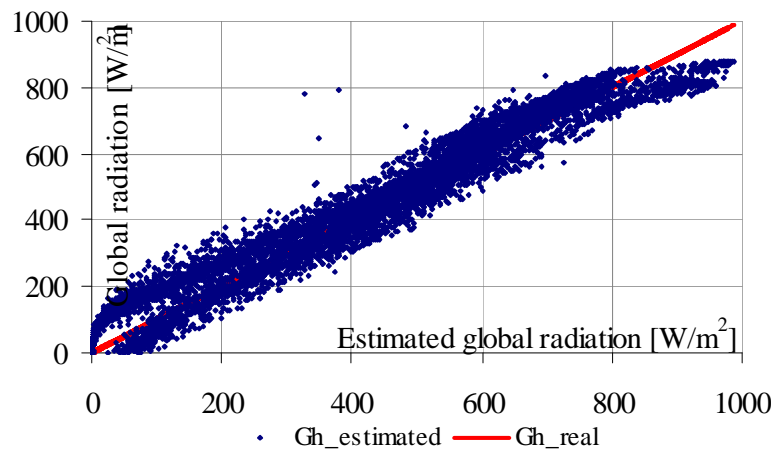

Fig. 1. Global solar radiation with real and estimated data for all days with clear sky conditions

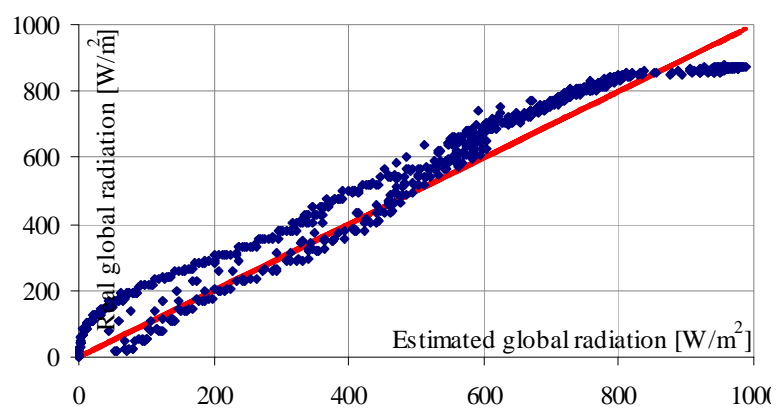

Fig. 2. Global solar radiation with real and estimated data for June and July months, days with clear sky conditions

In Figure 3, the estimated and real curves of the global solar radiation for clear sky days specific to different months are presented (January, March, June, July, October and December). It can be observed that: 
- for every month presented, the global solar radiation curves simulated with the proposed equation by this study, estimate in a satisfactory manner the real radiation curves;

- as mentioned before, after analyzing Figure 1 and 2, for the summer months June and July, the global solar

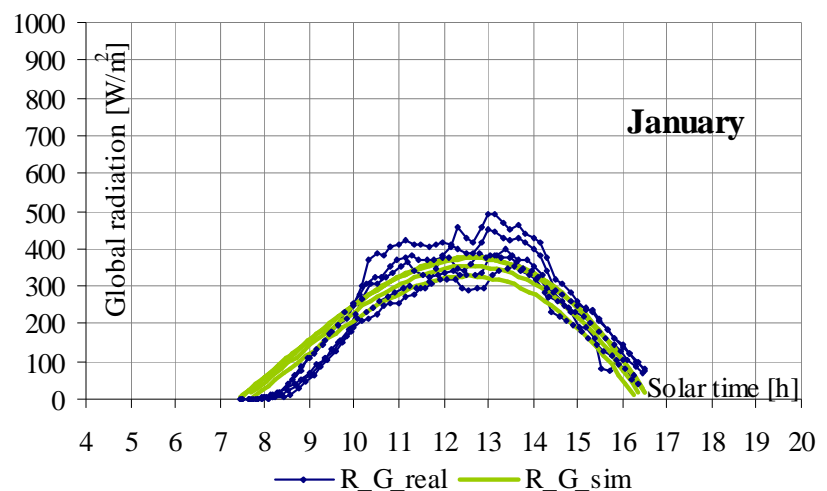

a)

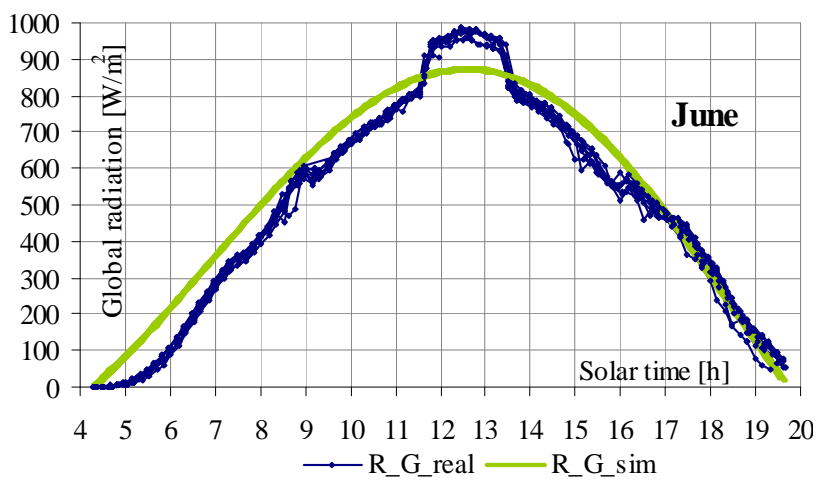

c)

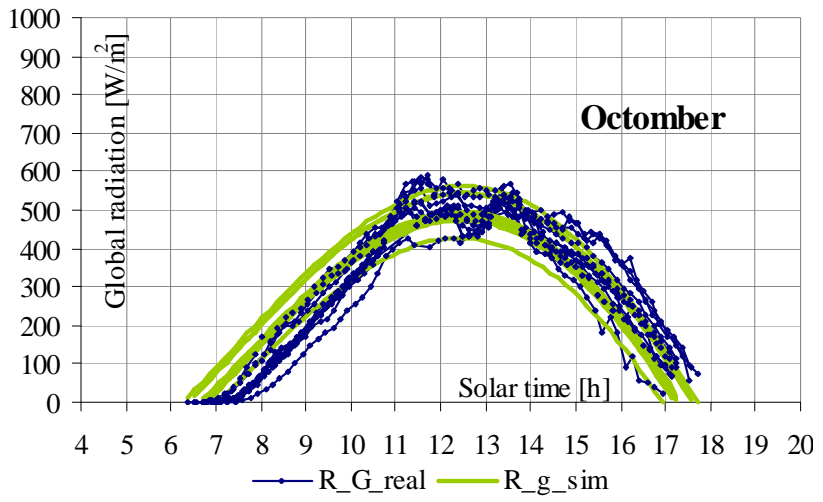

e) radiation with values higher than $800 \mathrm{~W} / \mathrm{m}^{2}$ is slightly underestimated;

- the estimation model simulates satisfactory the real variation curves in the afternoon and sunset period, with a slightly underestimation in the morning period.

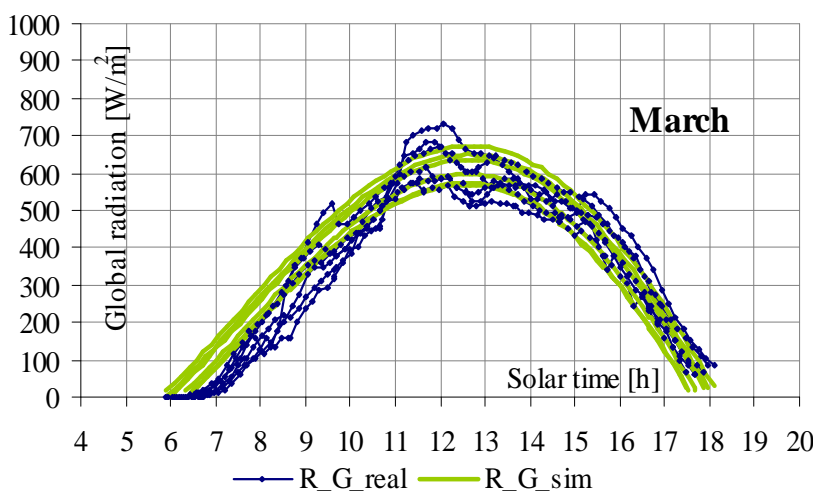

b)

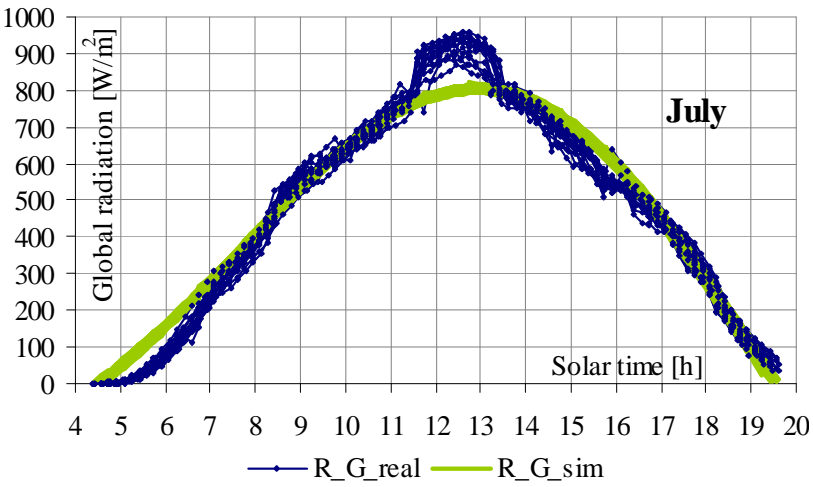

d)

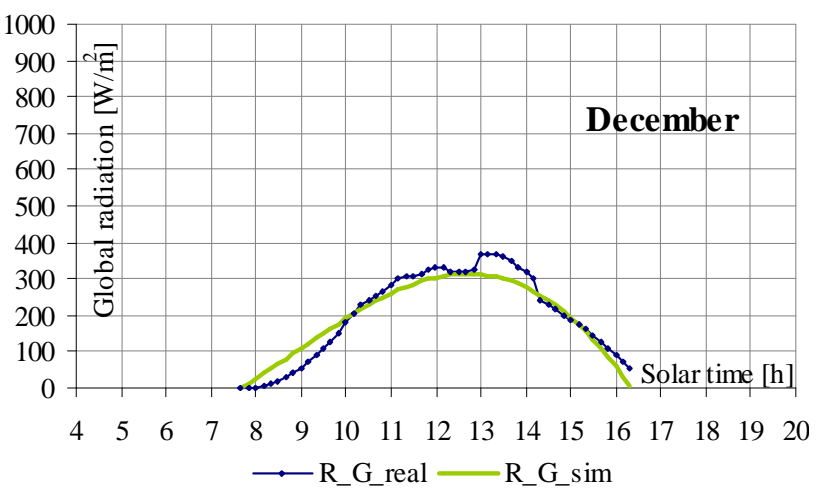

f)

Fig. 3. Global solar radiation, variation curves with real and simulated data

In Figure 4 the variation curves of the global solar radiation for values higher than $800 \mathrm{~W} / \mathrm{m}^{2}$ were extracted and superimposed with the variation curves of the altitudinal angle for values higher than $45^{\circ}$ (maximum value is $68^{\circ}$ ), depending of solar time.

It can be observed that the maximum daily values of the global solar radiation are not registered when the altitudinal angle has the maximum daily values (for 12 hour solar time). Actually the maximum value of the daily radiation is registered with a 'delay' (in Figure 4 the maximum values for the altitudinal angle do not match temporal with the global radiation maximum values) between 12 and 13 solar time.

A very important consequence of this inconsistency is represented by the asymmetry towards 12 solar time and the fact that the radiation has higher values on the sunset period.

In Figure 5, the variation curves with real and estimated data $\left(>800 \mathrm{~W} / \mathrm{m}^{2}\right)$ of the global radiation are presented, 
depending on solar time. It can be observed that the maximum values for the real and estimated curves are registered between 12 and 13 solar time interval; thus it can be said that the curves obtained with the proposed equations succeeded to model the 'delay' (asymmetry) of the real curves, the only inconvenient being the slightly underestimation of the maximum values of the global radiation, Figure 6.

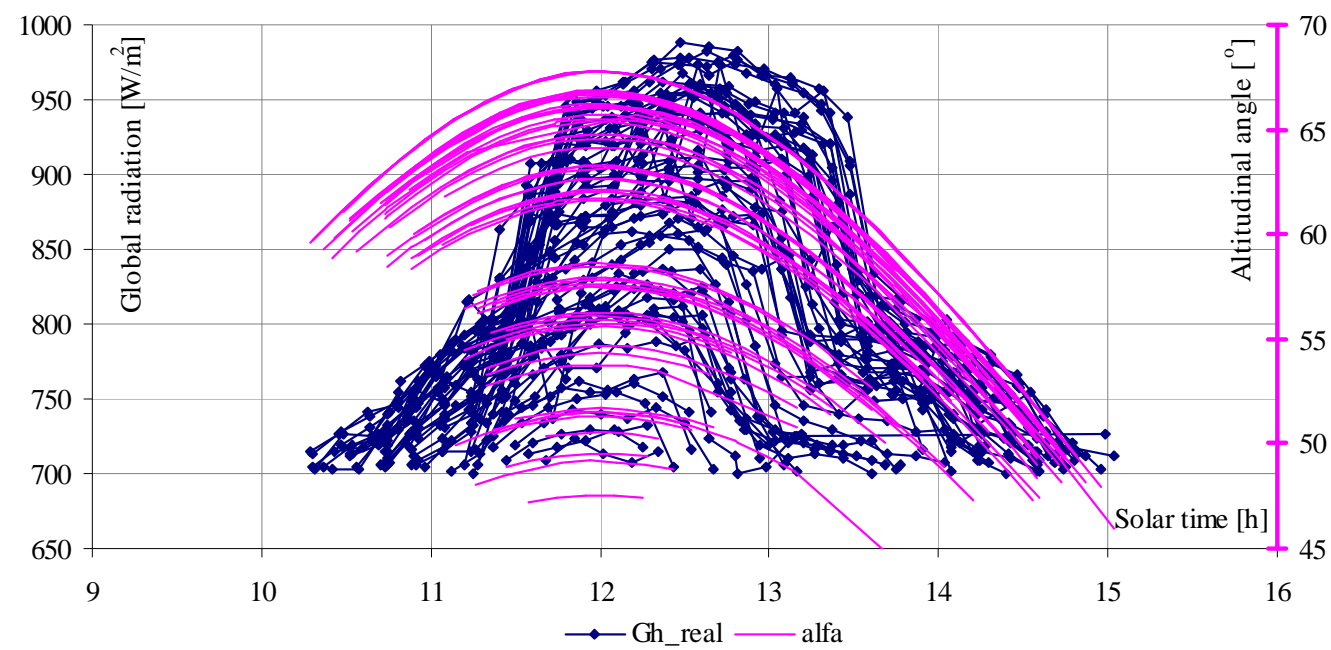

Fig. 4. Variation curves with real data for global solar radiation and variation curves for the altitudinal angle, clear sky days

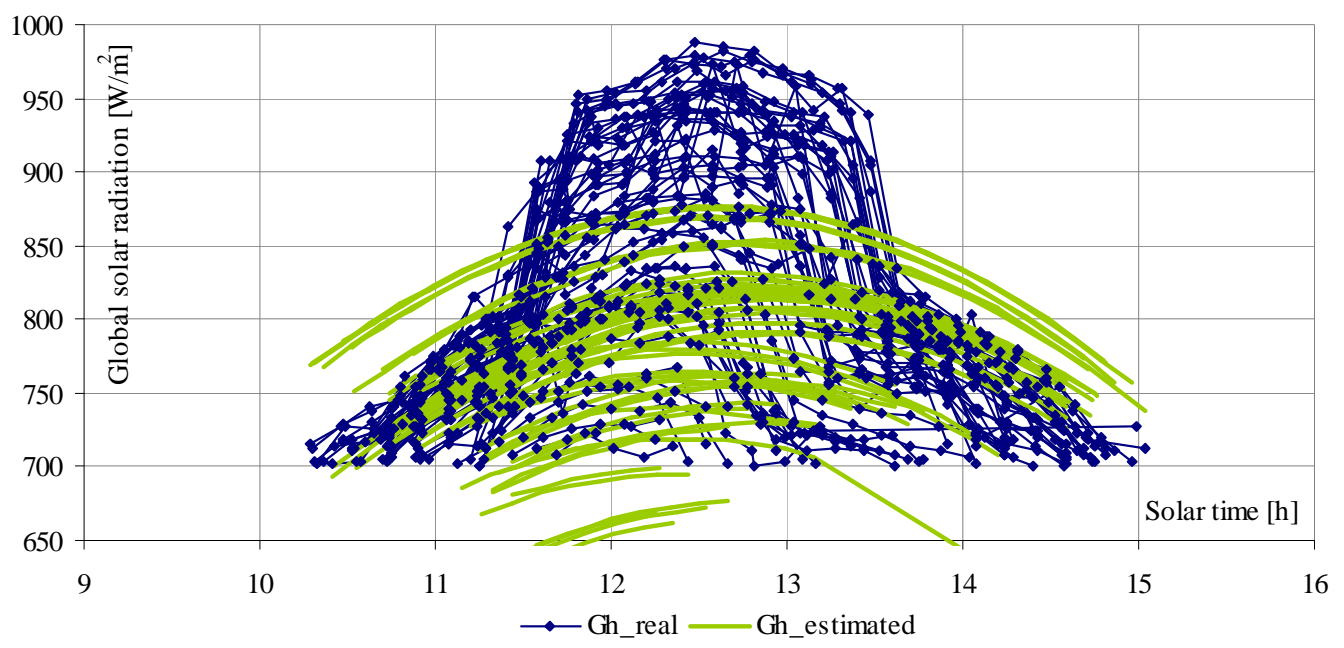

Fig. 5. Global solar radiation, variation curves with real and simulated data, clear sky days

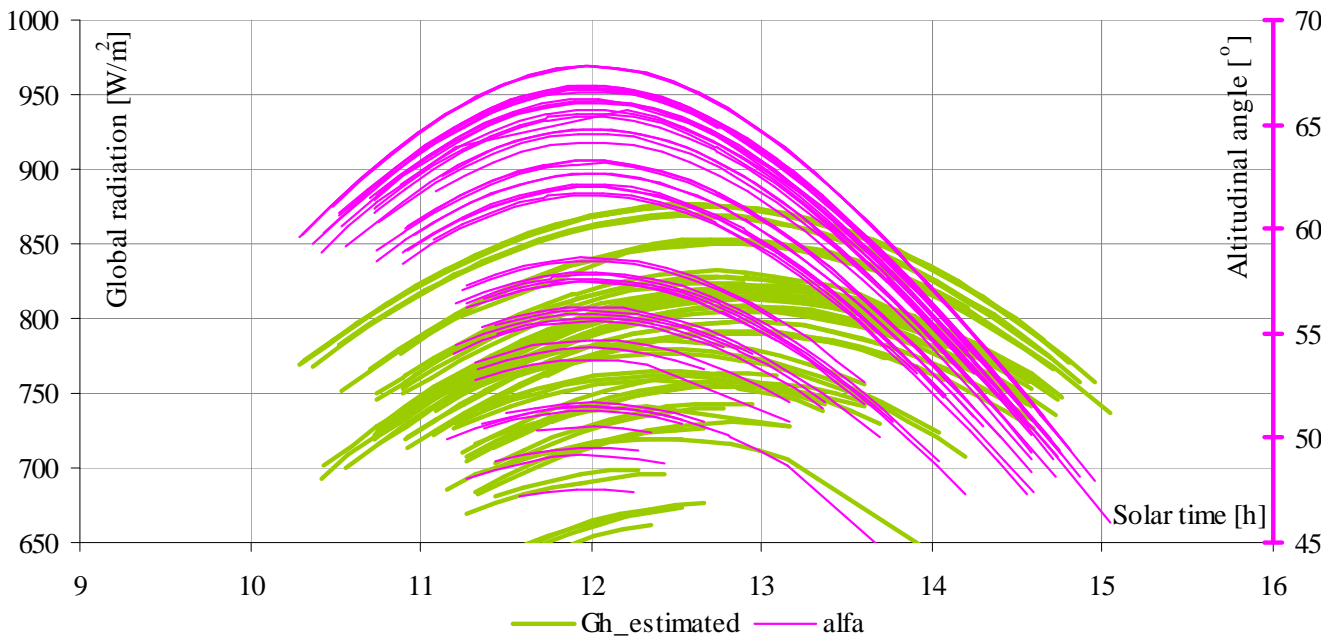

Fig. 6. Global solar radiation curves generated with estimated data with the proposed equations, and the variation curves of the altitudinal angle, clear sky days 
The delay phenomenon is due to the climatic phenomenon of thermal inversion that characterizes a basin area. [4]

\section{Model estimation performance}

In order to determine the performance of the equations proposed for the estimation of global solar radiation for Braşov urban area, two of the most utilized statistic indicators will be used: RMSE - root mean square error and MBE - mean bios error ([5], [6] and [7]).
For a correct analyze of the proposed model performances, these indicators will be calculated daily monthly and annually.

Figure 7 and 8 present the daily values for MBE and RMES in $\mathrm{kW} / \mathrm{m}^{2}$. The values of MBE fit in a range of 0.012 and $0 \mathrm{kWh} / \mathrm{m}^{2}$ (Figure 7) and the RMSE values between 0.04 and $0.12 \mathrm{kWh} / \mathrm{m}^{2}$ (Figure 8 ). So the errors variation domain is narrow, about $120 \mathrm{~W} / \mathrm{m}^{2}$ that leads to the conclusion that the proposed model estimates in a high manner the real global radiation.

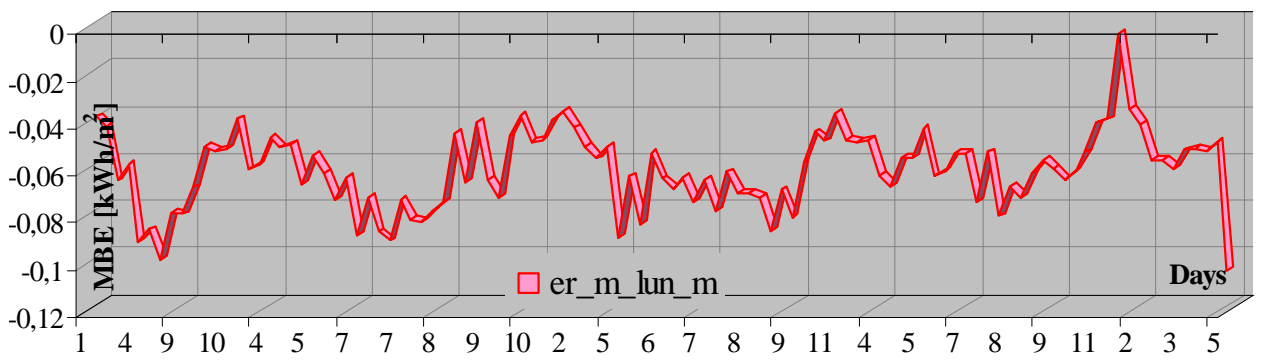

Fig. 7. Daily errors - MBE $\left[\mathrm{kW} / \mathrm{m}^{2}\right]$

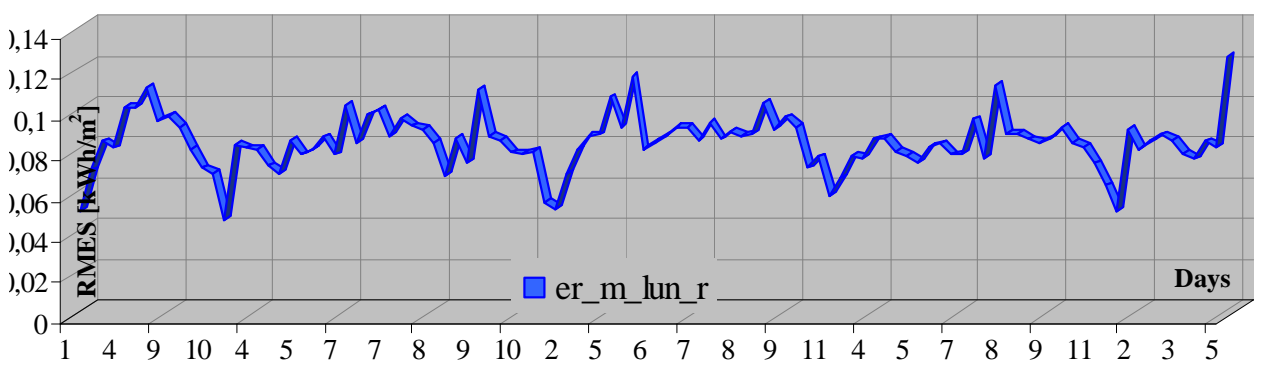

Fig. 8. Daily errors - RMES $\left[\mathrm{kW} / \mathrm{m}^{2}\right]$

Table II. - Monthly errors, MBE and RMES

\begin{tabular}{|c|c|c|c|c|c|c|c|c|}
\hline \multirow{3}{*}{ Month } & \multicolumn{8}{|c|}{ MBE and RMSE monthly errors } \\
\hline & \multicolumn{4}{|c|}{$\mathrm{MBE}\left[\mathrm{kWh} / \mathrm{m}^{2}\right]$} & \multicolumn{4}{|c|}{ RMSE $\left[\mathrm{kWh} / \mathrm{m}^{2}\right]$} \\
\hline & 2006 & 2007 & 2008 & 2009 & 2006 & 2007 & 2008 & 2009 \\
\hline January & -0.0389 & & -0.0365 & & 0.0507 & & 0.0515 & \\
\hline February & & & -0.0481 & & & & 0.0756 & \\
\hline March & -0.0554 & -0.0601 & -0.0565 & -0.0499 & 0.0785 & 0.0822 & 0.0872 & 0.0777 \\
\hline April & -0.0752 & -0.0501 & -0.0518 & -0.0587 & 0.0919 & 0.0743 & 0.0879 & 0.0811 \\
\hline May & -0.0868 & -0.0618 & -0.0796 & -0.0440 & 0.1013 & 0.0811 & 0.1053 & 0.0741 \\
\hline June & & -0.0741 & -0.0633 & -0.0600 & & 0.0867 & 0.0859 & 0.0813 \\
\hline July & -0.0993 & -0.0800 & -0.0704 & -0.0610 & 0.1112 & 0.0920 & 0.0891 & 0.0840 \\
\hline August & & -0.0802 & -0.0758 & -0.0745 & & 0.0910 & 0.0925 & 0.0976 \\
\hline September & -0.0562 & -0.0757 & -0.0616 & -0.0616 & 0.0857 & 0.0936 & 0.0868 & 0.0868 \\
\hline October & -0.0454 & -0.0510 & -0.0580 & -0.0580 & 0.0791 & 0.0808 & 0.0830 & 0.0830 \\
\hline November & -0.0399 & -0.0403 & -0.0372 & -0.0415 & 0.0464 & 0.0548 & 0.0577 & 0.0738 \\
\hline December & & & -0.0490 & & & & 0.0663 & \\
\hline
\end{tabular}


The monthly calculated values for the statistic indicators are presented in Table II. The smallest MBE monthly value was registered for January $2008-0.0365 \mathrm{kWh} / \mathrm{m}^{2}$, and the highest for June $2006-0.0993 \mathrm{kWh} / \mathrm{m}^{2}$. Referring to RMSE, November 2006 has the smallest value 0.0464 $\mathrm{kWh} / \mathrm{m}^{2}$, and July 2006 the highest, about 0.1112 $\mathrm{kWh} / \mathrm{m}^{2}$.

The highest errors have been obtained for the summer months (during the summer, the thermal inversion phenomenon manifests the greatest influence over the solar radiation), meanwhile for the cold months the lowest values for the errors were obtained.

Annually the relative standard deviation ranges between 0.0652 and $-0.060 \mathrm{~kW} / \mathrm{m}^{2}$ (the year 2010 is not complete, that is the reason it has a smaller error, $0.054 \mathrm{~kW} / \mathrm{m}^{2}$, Figure $9, \mathrm{a})$. The error domain range is limited, about $0.0052 \mathrm{~kW} / \mathrm{m}^{2}$.

Figure 9,b presents the annually variation for RMES, the variation interval is about $0.004 \mathrm{~W} / \mathrm{m}^{2}$, with it's inferior limit of $0.084 \mathrm{~kW} / \mathrm{m}^{2}$ for 2006 and superior limit for 2009 of $0.088 \mathrm{~kW} / \mathrm{m}^{2}$.

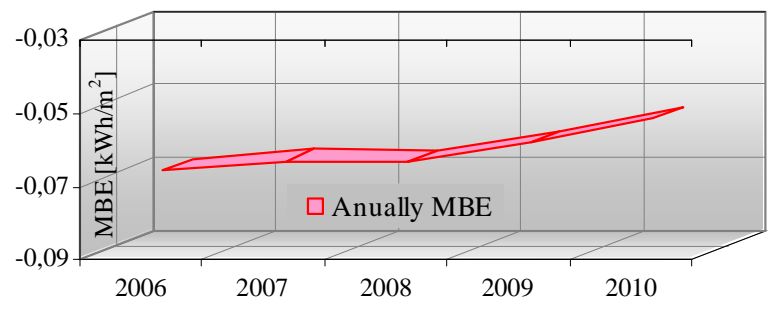

a)

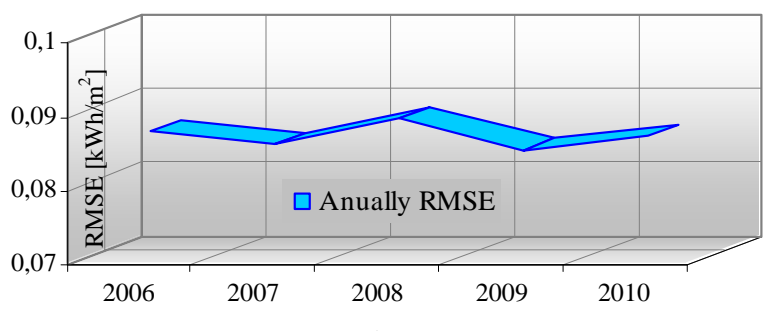

b)

Fig. 9. Annually errors, MBE $\left[\mathrm{kW} / \mathrm{m}^{2}\right]$ and RMES $\left[\mathrm{kW} / \mathrm{m}^{2}\right]$

The performances of the proposed model (characterized by 12 equations specific to every month) for estimating the global solar radiation for Braşov urban area have been confirmed based on the application of statistical indicators MBE and RMSE.
It can be said that satisfactory results are obtained for daily calculated errors as well as for monthly and annually determinations.

\section{Conclusion}

For a mathematical estimation of the global solar radiation accordingly to the reality (and implicitly of the direct and diffuse one) it is recommendable to take into consideration both the climatic and geographical characteristics of every site, and the influence of the urban environment over the meteorologic parameters that intervene in the radiation expression.

From the analysis of the statistical indicators results that the new proposed model estimates in a good manner the real variation of the global solar radiation for Braşov urban area.

\section{Acknowledgement}

This paper is supported by the Sectoral Operational Programme Human Resources Development (SOP HRD), financed from the European Social Fund and by the Romanian Government under the contract number POSDRU/6/1.5/S/6 and POSDRU/88/1.5/S/59321.

\section{References}

[1]. M. Păulescu, Algoritmi de estimare a energiei solare. Editura Matrix Rom, Bucureşti, (2004), (in Romanian), ISBN:973-685-951-7.

[2]. M. Păulescu, Z. Schlett, Performance assessment of global solar irradiation models under Romanian climate, Renewable Energy 29, (2004), pp. 767-777.

[3]. E. Eftimie, Beam Horizontal Irradiance Simulation for Braşov Urban Area - Clear Sky Model. Advances, in Environmental \& Geological Science \& Engineering, (2009), pp. 224-229.

[4]. M. Marcu, V. Huber, Air Thermal Stratification in the Depression Area Forms, in Phytogeographical Implications, Annals I.C.A.S., 46, (2003), pp. 141-150.

[5]. J. Almorox, M. Benito and C. Hontoria, Estimation of monthly Ångström-Prescott equation coefficients from measured daily data in Toledo, Spain. Renewable Energy 30, (2005), pp. 931-936.

[6]. J. Almorox, M. Benito and C. Hontoria, Statistical validation of daylenght definitions for estimation of global solar radiation in Toledo, Spain. Energy Conversion \& Management 46, (2005), pp. 1465-1471.

[7]. C.P Jacovides, Statistical procedures for the evaluation of evapotranspiration computing models. Agriculture Water Management 27, (1995), pp. 365-371. 